\title{
Characterization of resistance profile (intensity and mechanisms) of Anopheles gambiae in three communes of northern Benin, West Africa
}

\author{
Casimir Dossou Kpanou ${ }^{1,2^{*}}$, Hermann W. Sagbohan ${ }^{1,2}$, Fortuné Dagnon ${ }^{3,6}$, Germain G. Padonou ${ }^{1,2}$, \\ Razaki Ossè ${ }^{1,4}$, Albert Sourou Salako 1,2, Aboubakar Sidick' , Wilfried Sewadé1, André Sominahouin 1,2, \\ Patrick Condo 3 , Saadani Hassani Ahmed ${ }^{3}$, Daniel Impoinvil ${ }^{5}$ and Martin Akogbéto ${ }^{1,2}$
}

\begin{abstract}
Background: The selection and the spread of insecticide resistance in malaria vectors to the main classes of insecticides used in vector control tools are a major and ongoing challenge to malaria vector control programmes. This study aimed to determine the intensity of vector resistance to insecticides in three regions of Benin with different agro-ecological characteristics.

Methods: Larvae of Anopheles gambiae sensu lato (s.l.) were collected from September to November 2017 in different larval sites in three northern Benin communes: Parakou, Kandi and Malanville. Two to five-day-old, non-blood-fed, female mosquitoes were exposed to papers impregnated with deltamethrin, permethrin and bendiocarb at dosages of $1 \times$ the diagnostic dose, $5 \times$ and $10 \times$ to determine the intensity of resistance in these vectors. Molecular frequencies of the $k d r$ L1014F and ace-1R G119S insecticide resistance mutations and levels of detoxification enzymes were determined for mosquitoes sampled at each study site.

Results: Resistance to pyrethroids (permethrin and deltamethrin) was recorded in all three communes with mortality rates below $60 \%$ using the diagnostic dose (1x). The results obtained after exposure of An. gambiae to permethrin $10 \times$ were $99 \%$ in Kandi, 98\% in Malanville and 99\% in Parakou. With deltamethrin 10x, mortality rates were 100\% in Kandi, $96 \%$ in Malanville and $73 \%$ in Parakou. For the diagnostic dose of bendiocarb, suspected resistance was recorded in the communes of Malanville (97\%) and Kandi (94\%) while sensitivity was observed in Parakou (98\%). Using the $10 \times$ dose, mortality was $98 \%$ in Kandi, 100\% in Malanville and $99 \%$ in Parakou. The frequencies of the $k d r$ L1014F allele varied between 59 and 83\% depending on the sites and species of the An. gambiae complex, while the frequency of the ace-1R G119S gene varied between 0 and 5\%. Biochemical tests showed high levels of oxidase and esterase activity compared to the susceptible colony strain of An. gambiae sensu stricto (Kisumu strain).
\end{abstract}

Conclusion: Anopheles gambiae showed a generalized loss of susceptibility to permethrin and deltamethrin but also showed moderate to high intensity of resistance in different regions of Benin. This high intensity of resistance is a potential threat to the effectiveness of vector control.

\footnotetext{
*Correspondence: casimirkpanou@yahoo.com

${ }^{1}$ Centre de Recherche entomologique de Cotonou (CREC), Cotonou, Bénin
}

Full list of author information is available at the end of the article

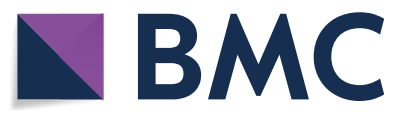

(c) The Author(s) 2021. This article is licensed under a Creative Commons Attribution 4.0 International License, which permits use, sharing, adaptation, distribution and reproduction in any medium or format, as long as you give appropriate credit to the original author(s) and the source, provide a link to the Creative Commons licence, and indicate if changes were made. The images or other third party material in this article are included in the article's Creative Commons licence, unless indicated otherwise in a credit line to the material. If material is not included in the article's Creative Commons licence and your intended use is not permitted by statutory regulation or exceeds the permitted use, you will need to obtain permission directly from the copyright holder. To view a copy of this licence, visit http://creativecommons.org/licenses/by/4.0/. The Creative Commons Public Domain Dedication waiver (http://creativecommons.org/publicdomain/zero/1.0/) applies to the data made available in this article, unless otherwise stated in a credit line to the data. 
Keywords: Insecticide resistance, Intensity, Anopheles gambiae, Pyrethroids, Bendiocarb

\section{Background}

Malaria persists as a major public health problem in sub-Saharan Africa [1]. Benin, like most countries in sub-Saharan Africa, continues to bear a heavy burden of malaria. While the prevalence of malaria is $15 \%$ in the general population, this rate is even higher among children under five years of age (37.2\%) [2]. Vector control is of paramount importance in the fight against this disease. Current vector control tools mainly include long-lasting insecticidal nets (LLINs) and indoor residual spraying (IRS).

However, over the past decade, studies in Benin have reported an expansion of insecticide resistance in malaria vectors [3-6], particularly in Anopheles gambiae sensu lato (s.l.), to the different insecticide classes. Resistance has been detected in all pyrethroids used in the impregnation of insecticide-treated nets (ITNs). Carbamates, such as bendiocarb and propoxur, used for IRS, have also been shown to have reduced efficacy against An. gambiae in the Atacora department [3]. For organophosphates, a decrease in sensitivity of $A n$. gambiae to compounds such as fenitrothion has also been observed [3]; however, although no resistance to pirimiphos-methyl has been recorded [7] despite its use in Atacora for IRS from 2013 to 2016, resistance is a dynamic phenomenon and there is a continuous threat of resistance emergence. This has already been shown by authors from other countries $[8,9]$.

Phenotypic insecticide resistance is assessed using the World Health Organization (WHO) insecticide susceptibility tests [10] and the Centers for Disease Control and Prevention (CDC) bottle bioassay for determining insecticide resistance in vectors [11]. Many vector control programmes screen for resistance using only the diagnostic dose $(1 \times)$ of the insecticides. While these tests provide useful information on the presence or absence of resistance in mosquito populations, they do not provide details on the intensity of insecticide resistance in non-susceptible populations. For example, if two different mosquito populations had mortality rates of $50 \%$ at $1 \times$, but when exposed to $5 \times$ and $10 \times$, one population achieved $100 \%$ mortality, but the other remained at $\sim 50 \%$, the $1 \times$ assay would have erroneously led a decision-maker to believe that the populations were 'equivalent' in their resistance. In actuality, the behaviour and the receptivity to control of these two mosquito populations would be different when in contact with insecticide-based vector control tools (LLINs or IRS).
This work aimed to measure the intensity of insecticide resistance in malaria vectors from rice- and cotton-growing environments under high agricultural insecticide pressure against crop pests by exposing them to high doses of bendiocarb, deltamethrin and permethrin. This was done to quantify the level of resistance occurring in northern Benin.

Molecular and biochemical tests were also performed to provide a characterization of the mechanisms conferring insecticide resistance in mosquito populations.

\section{Methods}

\section{Study area}

The study was carried out in three communes in northern Benin (Parakou, Kandi, Malanville) between September and November 2017 (Fig. 1). These three communes were selected because of their different agro-ecological characteristics.

The commune of Parakou in the department of Borgou is at an average altitude of $350 \mathrm{~m}$ above sea level with a modest relief (i.e., the geographical difference between the highest and lowest elevation point in an area). It covers an area of $441 \mathrm{sq} \mathrm{km}$ with a population of 254,254 inhabitants [12]. In Parakou, the climate is humid and tropical (South-Sudanese climate). It is characterized by an annual alternation of a rainy season (May to October) and a dry season (November to April). The lowest temperatures are recorded in December-January. The average annual rainfall is $1,200 \mathrm{~mm}$, with a maximum occurring between July and September. The landcover of Parakou is predominately urban. This town has not conducted an IRS campaign so far, but cotton is widely grown with extensive use of insecticides to control agricultural pests. Also, people frequently use LLINs, aerosol sprays and smoke coils to protect themselves against mosquito bites. There is market gardening (small-scale commercial production of cash crops) occurring along the commune perimeter, which serves as prolific larval habitats for $A n$. gambiae on both sides of the city.

The commune of Kandi is located in the centre of the Alibori department in the agro-ecological zone of the cotton basin. It is an area with high cotton production and therefore intensive use of insecticides. These insecticides belong to the class of pyrethroids, carbamates and organophosphates [13]. In addition, this commune benefitted from intradomiciliary spraying based on pirimiphos-methyl in 2017. The Kandi commune covers an area of $3,421 \mathrm{sq} \mathrm{km}$, (i.e., about $13 \%$ of the entire department) with a population of 177,683 inhabitants 


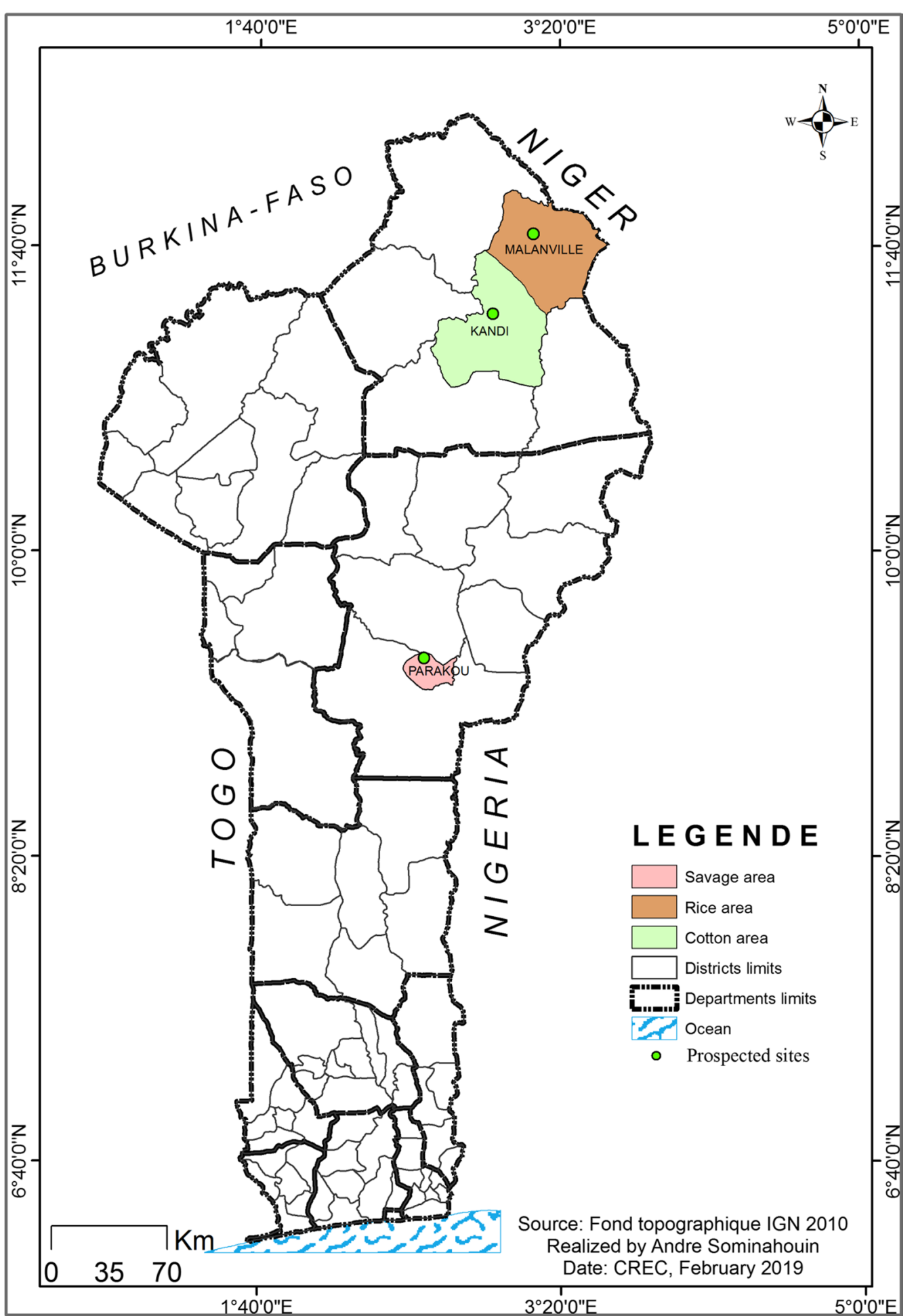

Fig. 1 Study area showing the rice-growing commune (Malanville), the cotton-growing commune in Kandi, and the savage area in Parakou

[12]. Kandi has an altitude of 200 to $300 \mathrm{~m}$ and is cut by steep valleys, including the Sota valley and the Alibori valley in the east and the west, respectively. The relief is made up of sandstone plateaux cut by the valleys of the Sota and Alibori rivers, which are the two main rivers of the commune. The climate is North-Sudanese with a 
dry season from November to April and a rainy season from May to October. The average rainfall is between 800 and 1,300 mm per year. The dominant winds are the harmattan in the dry season and the monsoon from April to October. The average relative humidity reaches $80 \%$ during the rains but drops to $35 \%$ during the dry season. The major sources of water are the tributaries of the Alibori and the Sota [14].

The commune of Malanville, also in the Alibori department, is located in the extreme north of the Republic of Benin. It covers an area of $3,016 \mathrm{sq} \mathrm{km}$, of which 8,000 ha is arable land. Its population is 168,006 inhabitants [12]. Like the rest of the country, the commune of Malanville regularly benefits from LLIN campaigns. Its average altitude is $200 \mathrm{~m}$ above sea level. Its climate is of the NorthSudanese type marked by a dry season from November to April. The annual average rainfall recorded is $750 \mathrm{~mm}$. Malanville is crossed longitudinally (east to west) by the Niger River with its tributaries, including the Alibori, the Mékrou and the Sota river, which flood during August and September. The commune of Malanville is an area of high rice production; rice plots serve as larval habitats for An. gambiae s.l. The application of tonnes of fertilizers and herbicides applied to the rice plots every year has contributed to the emergence of insecticide resistance in this commune [15].

\section{Mosquito collection}

Anopheles gambiae larvae were collected during the study period from different larval sites in the communes of Parakou, Kandi and Malanville using standard dippers and containers. The collected larvae were sorted, kept in labelled jars, and transported to the insectary of the Centre for Entomological Research of Cotonou (CREC) for rearing. Emerging adults from the field larval collections, which were placed in cages, were fed on $10 \%$ honey solution and kept at $27 \pm 2{ }^{\circ} \mathrm{C}$ and relative humidity of $72 \pm 5 \%$. Morphologically identified 2 to 5 -day-old adult females were used for susceptibility testing to various insecticides and biochemical analyses.

\section{Susceptibility testing of collected Anopheles gambiae to insecticides}

Susceptibility tests using WHO tubes were performed according to the WHO protocol [10] with non-blood-fed female An. gambiae aged 2-5 days. These mosquitoes were exposed to different doses of WHO-impregnated papers: deltamethrin, permethrin and bendiocarb. Deltamethrin and permethrin are the most common insecticides found on mosquito nets in Benin, and bendiocarb was the insecticide formerly used in some regions of Benin (Oueme and Atacora) from 2008 to 2012 but to which vectors have developed resistance [3]. The doses of the different tested insecticides were: deltamethrin $0.05 \%(1 \times)$; deltamethrin $0.25 \%(5 \times)$; deltamethrin $0.5 \%$ $(10 \times)$; permethrin $0.75 \%(1 \times)$; permethrin $3.75 \%(5 \times)$; permethrin $7.5 \%(10 \times)$; bendiocarb $0.1 \%(1 \times), 0.5 \%$ $(5 \times)$ and $1 \%(10 \times)$. The use of higher concentrations $(5 \times$ and $10 \times)$ allows for the determination of the intensity of insecticide resistance in these populations and their ability to tolerate insecticide doses that are higher than the diagnostic dose.

For each dose of insecticide, approximately 20 nonblood-fed female mosquitoes were introduced into each tube lined with insecticide-impregnated paper. For each insecticide and dose, four test tubes lined each with the respective insecticide-impregnated paper were used. For each assay, two control tubes with impregnated paper with insecticide diluent only (i.e., no insecticide) were used; each tube had $\sim 20$ non-blood-fed female mosquitoes. After $60 \mathrm{~min}$ of exposure, the mosquitoes were transferred to observation tubes containing untreated paper, with free access to $10 \%$ honey solution. At the end of the tests, living and dead specimens were used for molecular identification of species and determination of resistance mechanisms.

\section{Identification of Anopheles gambiae complex species and molecular characterization of $k d r$ L1014F and ace-1 G119S resistance alleles}

Using previously established protocols [16], live and dead mosquitoes from the susceptibility tests from all doses were analysed by PCR to determine the species of the $A n$. gambiae complex.

The genotypes of the $k d r$ (knock-down resistance) L1014F mutation in the sodium channel associated with resistance to pyrethroid insecticides and the ace-1 G119S (insensitive acetylcholinesterase) mutation associated with resistance to carbamates and organophosphates were determined according to the protocols of Martinez et al. [17] and Weill et al. [18], respectively. The allelic frequency of these two mutations was evaluated at each site to analyse correlations with phenotypic resistance.

\section{Enzymatic tests on microplates}

Approximately 30-50 An. gambiae (F1) females from each site, aged 2-5 days and not previously used for any insecticide test, were used for biochemical analyses. Before these analyses, these mosquito specimens were stored at $-80{ }^{\circ} \mathrm{C}$ in dry microcentrifuge tubes. Biochemical enzyme assays [19] were carried out to compare the level of activity of mixed oxidases (MFO), non-specific esterases ( $\alpha$ and $\beta$-esterases) and glutathione S-transferases (GST) in Parakou, Kandi and Malanville mosquito populations with that of An. gambiae sensu stricto (s.s.) Kisumu, a susceptible 
laboratory strain. Since enzymes degrade rapidly at room temperature, mosquitoes were ground on ice in $200 \mu \mathrm{l}$ of distilled water and the extract was centrifuged at 12,000 rpm for $2 \mathrm{~min}$. For GST, $10 \mu \mathrm{l}$ of mosquito grindings in two replicates were put into each Nunc plate well to which $200 \mu \mathrm{l}$ of a solution of reduced glutathione and 1-chloro-2,4-dinitrobenzene (CDNB)) was added. Concerning MFOs, after putting $20 \mu \mathrm{l}$ of crushed material in two replicates in each well, $80 \mu \mathrm{l}$ of $0.0625 \mathrm{M}$ potassium phosphate buffer (KHPO4) $\mathrm{pH}=7.2$ and $200 \mu \mathrm{l}$ of $0.25 \mathrm{M}$ tetramethyl benzidine (TMBZ) solution pH 5.0 and, $25 \mu \mathrm{l}$ of a $3 \%$ hydrogen peroxide solution were added in each well. For the nonspecific esterases, $90 \mu \mathrm{L}$ of two replicates of shredded material were added to each plate well, $90 \mu \mathrm{L}$ of $1 \%$ triton phosphate buffer (PBS) pH 6.5, $100 \mu \mathrm{L}$ of a solution composed of $0.3 \mathrm{M}$ alpha-Naphthyl acetate (or betaNaphthyl acetate) and Triton PBS pH 6.5, water and Fast Garnett Salt solution. Readings for each enzyme activity were taken as an endpoint at $340 \mathrm{~nm}, 630 \mathrm{~nm}$ and $550 \mathrm{~nm}$ for GST, MFO and non-specific esterases, respectively.

\section{Data analysis}

The resistance status of malaria vectors was determined as follows:

- $\geq 98 \%$ mortality $24 \mathrm{~h}$ after insecticide exposure, the An. gambiae population is susceptible;

- Between 90 and $97 \%$ mortality $24 \mathrm{~h}$ after insecticide exposure, the An. gambiae population is suspected of being resistant (requires confirmation);
- $<90 \%$ mortality $24 \mathrm{~h}$ after insecticide exposure, the An. gambiae populations is resistant.

No mortality was recorded in controls. Therefore, Abbott's formula was not necessary to correct the mortality rates.

The resistance status of the tested mosquito populations was determined according to WHO criteria [10]. The mortality rates of An. gambiae populations from the three different sites were compared using a stratified $2 \times 3$ contingency table and Pearson's $x^{2}$-test in the statistical software, $R 2.15$. The strata in the $2 \times 3$ contingency table included the insecticide and the dosage. The allelic frequencies of the $k d r$ L1014F and ace-1 G119S genes were analysed to assess their variability across mosquito populations. Using SPSS ${ }^{\circledR}$ (SPSS Inc. Released 2009. PASW Statistics for Windows, Version 18.0. Chicago: SPSS Inc.), a comparative measure of mean enzyme activities between the study sites was performed to assess the variation in enzyme activity of mosquito populations in each locality using one-way analysis of variance (ANOVA). Tukey's test was used to compare the means. Independent-samples t-test was performed to compare enzyme activity between field and laboratory (Kisumu) susceptible mosquitoes.

\section{Results \\ Susceptibility testing of collected Anopheles gambiae to insecticides}

A total of 2,501 female mosquitoes were exposed to insecticide-impregnated papers, of which 860 were from Malanville, 847 from Kandi, and 794 from Parakou (Tables 1, 2, 3). No mortality was recorded in the

Table 1 Mortality rate and resistance status of Anopheles gambiae s.l. from Malanville, Parakou and Kandi after exposure to papers impregnated with permethrin

\begin{tabular}{|c|c|c|c|c|c|c|c|}
\hline District & Insecticide/Dose & Total tested & $\begin{array}{l}\text { Mortality rate } \\
\text { (\%) }\end{array}$ & Nber dead/24 h & Nber alive & P-value & $95 \% \mathrm{Cl}$ \\
\hline Control & No & 50 & 0 & 0 & 50 & & \\
\hline \multirow[t]{3}{*}{ Kandi } & Per $1 \mathrm{x}$ & 96 & $52^{\mathrm{a}}$ & 50 & 46 & $<0,0001$ & {$[41,6-62,4]$} \\
\hline & Per $5 x$ & 100 & $92^{b}$ & 92 & 8 & & {$[84,8-96,5]$} \\
\hline & Per 10X & 99 & $99^{c}$ & 98 & 1 & & {$[94,5-100]$} \\
\hline \multirow[t]{3}{*}{ Malanville } & Per $1 \mathrm{x}$ & 93 & $16^{\mathrm{a}}$ & 15 & 78 & $<0,0001$ & {$[9,3-25,2]$} \\
\hline & Per $5 x$ & 96 & $91^{\mathrm{b}}$ & 87 & 9 & & {$[82,9-95,6]$} \\
\hline & Per 10X & 95 & $98^{b}$ & 93 & 2 & & {$[92,6-99,7]$} \\
\hline \multirow[t]{3}{*}{ Parakou } & Per $1 \mathrm{x}$ & 84 & $48^{\mathrm{a}}$ & 40 & 44 & $<0,0001$ & {$[36,6-58,8]$} \\
\hline & Per $5 x$ & 87 & $84^{b}$ & 73 & 14 & & {$[74,5-90,9]$} \\
\hline & Per 10X & 84 & $99^{c}$ & 83 & 1 & & {$[93,5-100]$} \\
\hline
\end{tabular}


Table 2 Mortality rate and resistance status of Anopheles gambiae s.l. from Malanville, Parakou and Kandi after exposure to papers impregnated with deltamethrin

\begin{tabular}{|c|c|c|c|c|c|c|c|}
\hline District & Insecticide/Dose & Total tested & $\begin{array}{l}\text { Mortality rate } \\
\text { (\%) }\end{array}$ & Nber dead/24h & Nber alive & P-value & $95 \% \mathrm{Cl}$ \\
\hline Control & No & 50 & 0 & 0 & 50 & & \\
\hline \multirow[t]{3}{*}{ Kandi } & Delta $1 \mathrm{x}$ & 89 & $16^{\mathrm{a}}$ & 14 & 75 & $<0,0001$ & {$[8,9-25]$} \\
\hline & Delta $5 x$ & 88 & $58^{b}$ & 51 & 37 & & {$[47-68,4]$} \\
\hline & Delta 10x & 96 & $100^{c}$ & 96 & 0 & & {$[96,2-100]$} \\
\hline \multirow[t]{3}{*}{ Malanville } & Delta $1 \mathrm{x}$ & 91 & $14^{\mathrm{a}}$ & 13 & 78 & $<0,0001$ & {$[7,8-23,2]$} \\
\hline & Delta $5 x$ & 91 & $86^{b}$ & 78 & 13 & & {$[76,8-92,2]$} \\
\hline & Delta 10x & 93 & $96^{c}$ & 89 & 4 & & {$[89,4-98,8]$} \\
\hline \multirow[t]{3}{*}{ Parakou } & Delta 1x & 90 & $40^{\mathrm{a}}$ & 36 & 54 & $<0,0001$ & {$[29,8-50,9]$} \\
\hline & Delta $5 x$ & 82 & $49^{a}$ & 40 & 42 & & {$[37,6-60,1]$} \\
\hline & Delta 10x & 96 & $73^{b}$ & 70 & 26 & & {$[62,9-81,5]$} \\
\hline
\end{tabular}

Mortality rate comparison by location which have the same letter do not differ significantly for the same dose in different populations at the 0.05 level using z-test; tbased on $x^{2}$-test

Table 3 Mortality rate and resistance status of Anopheles gambiae s.l. from Malanville, Parakou and Kandi after exposure to papers impregnated with bendiocarb

\begin{tabular}{|c|c|c|c|c|c|c|c|}
\hline District & Insecticide/Dose & Total tested & $\begin{array}{l}\text { Mortality rate } \\
(\%)\end{array}$ & Nber dead/24 h & Nber alive & P-value & $95 \% \mathrm{Cl}$ \\
\hline Control & No & 50 & 0 & 0 & 50 & & \\
\hline \multirow[t]{3}{*}{ Kandi } & Bendio 1x & 87 & 94 & 82 & 5 & 0,4334 & {$[87,1-98,1]$} \\
\hline & Bendio $5 x$ & 95 & 96 & 91 & 4 & & {$[89,6-98,8]$} \\
\hline & Bendio 10x & 97 & 98 & 95 & 2 & & {$[92,7-99,7]$} \\
\hline \multirow[t]{3}{*}{ Malanville } & Bendio 1x & 98 & 97 & 95 & 3 & 0,1574 & {$[91,3-99,4]$} \\
\hline & Bendio $5 x$ & 102 & 99 & 101 & 1 & & {$[94,7-100]$} \\
\hline & Bendio 10x & 101 & 100 & 101 & 0 & & - \\
\hline \multirow[t]{3}{*}{ Parakou } & Bendio $1 \mathrm{x}$ & 87 & 98 & 85 & 2 & 0,742 & [91,9-100] \\
\hline & Bendio $5 x$ & 91 & 99 & 90 & 1 & & [94-100] \\
\hline & Bendio 10x & 93 & 99 & 92 & 1 & & {$[94,2-100]$} \\
\hline
\end{tabular}

Mortality rate comparison by location which have the same letter do not differ significantly for the same dose in different populations at the 0.05 level using z-test; tbased on $\mathrm{X}^{2}$-test

controls. Therefore, Abbott's formula was not used to correct the mortality rates.

Pyrethroid resistance was recorded in all three communes with mortality rates below $60 \%$ (Table 1, Fig. 2). Of 91 mosquitoes in the Malanville population exposed to the diagnostic dose of deltamethrin (1x), only 13 were dead (14\%) (Table 2, Fig. 2). When Malanville mosquitoes were exposed to higher $5 \times$ and $10 \times$ doses of deltamethrin, mortality rates increased from $14 \%$ (for the $1 \times$ dose) to, respectively, 86 and 96\% (Table 2, Fig. 2). Despite increasing the deltamethrin concentration by five times the diagnostic concentration $(5 \mathrm{x})$, only $86 \%$ of the tested mosquitoes were killed and more than $14 \%$ continued to fly $24 \mathrm{~h}$ after observation. Even with a $10 \times$ concentration, not all mosquitoes were killed with deltamethrin (Table 2, Fig. 2). With permethrin $1 \mathrm{x}$ (diagnostic dose), only $16 \%$ were dead $24 \mathrm{~h}$ after the exposure time. With higher doses, $5 \times$ and $10 \mathrm{x}$, permethrin mortality rates increased from 16 to 91 and 98\%, respectively, for mosquitoes in Malanville (Table 1, Fig. 2). The trends recorded in Malanville for these pyrethroids (deltamethrin and permethrin) (Tables 1 and 2) are the same in Kandi and Parakou also showing an increase in mortality rates of An. gambiae exposed to multiple diagnostic doses, but without killing all mosquitoes.

For bendiocarb, suspected resistance was recorded in the communes of Malanville (97\%) and Kandi (94\%) while susceptibility was observed in Parakou (98\%). When mosquitoes in Malanville were exposed 


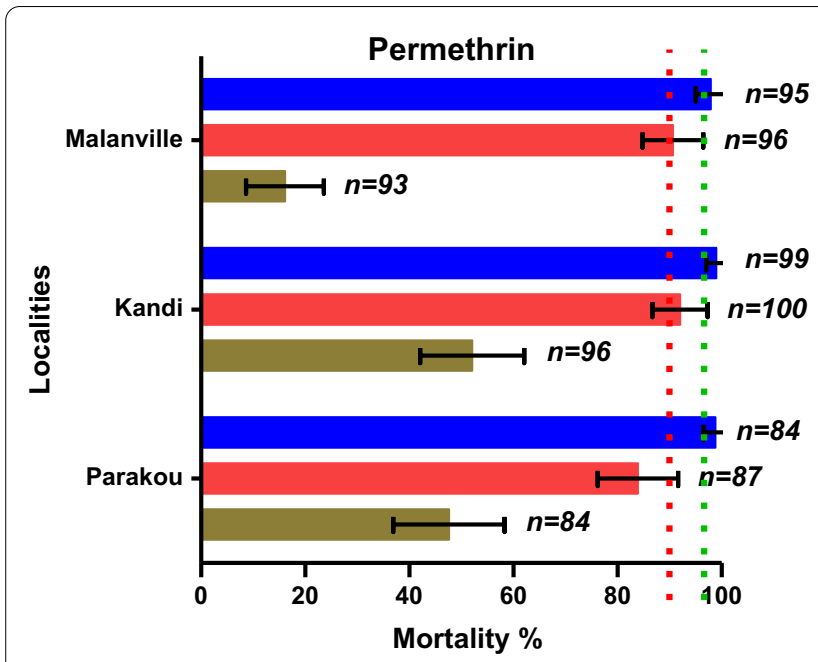

Per 1x Per 5x $\square$ Per 10x

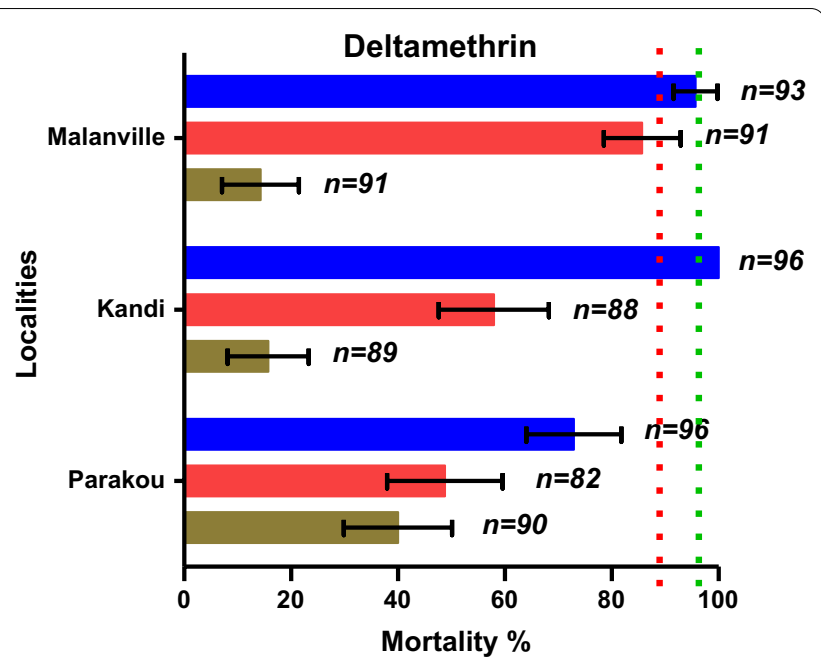

Delta 1x Delta 5x Delta 10x

Fig. 2 Mortality rate after exposure of Anopheles gambiae collected in Parakou, Kandi and Malanville to multiple doses of permethrin and deltamethrin diagnostic concentration, using WHO tubes bioassay

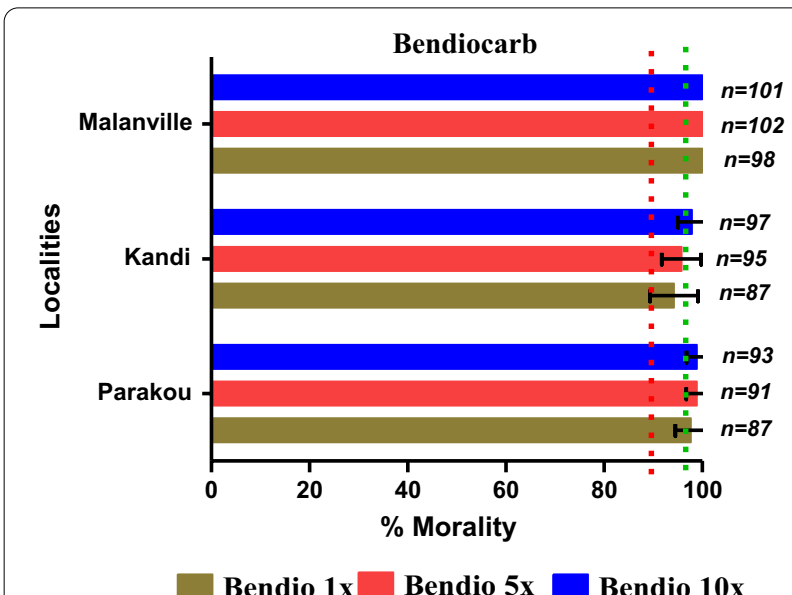

Fig. 3 Mortality rate after exposure of Anopheles gambiae collected in Parakou, Kandi and Malanville to multiple doses of bendiocarb diagnostic concentration, using WHO tubes to $5 \times$ and $10 \times$ higher doses of bendiocarb, mortality rates increased to 99 and $100 \%$, respectively (Table 3, Fig. 3), reflecting the sensitivity of the Malanville populations to these doses. Similar results were recorded with mosquitoes from Parakou with a mortality rate of $99 \%$ for bendiocarb $5 \times$ and 10x. However, with $A n$. gambiae populations in Kandi, even a tenfold higher concentration did not kill all mosquitoes with a mortality rate of $98 \%$.

There were significant mortality differences in Malanville, Kandi and Parakou at each individual insecticide-concentration combination of $1 \times, 5 \times$, and $10 \times$ deltamethrin, and $1 \times$ permethrin $(\mathrm{p}<0.001)$.

\section{Identification of Anopheles gambiae complex species} and molecular characterization of $k d r$ L1014F and ace-1 G119S resistance alleles

Species PCR analysis detected the presence of three species of An. gambiae in Parakou including: An. gambiae s.s. (94\%), Anopheles coluzzii (3\%) and Anopheles arabiensis (3\%). In Kandi, two species of this complex, namely An. gambiae s.s. (90\%) and An. arabiensis (10\%), were detected. (Tables 4 and 5).

The $k d r L 1014 F$ mutation allelic frequencies ranged from 0.59 in Malanvile for $A n$. coluzzii to 0.83 in Parakou for An. arabiensis (Table 4). For the ace-1 G119S mutation, the allelic frequencies were low ranging from 0.02 in Parakou to 0.05 in Kandi and Malanville (Table 5).

\section{Enzymatic tests on microplates}

Enzyme activity in An. gambiae in the three communes was higher compared to the reference Kisumu strain (Fig. 4, Table 6). The activity of non-specific esterases ( $\alpha$ and $\beta$ esterase) was significantly higher in Kandi populations compared to the Kisumu strain $(\mathrm{p}<0.05)$ (Fig. 4 , 
Table 4 The frequency of the kdr resistant allele (L1014F) observed in the different Anopheles gambiae complex species

\begin{tabular}{|c|c|c|c|c|c|c|c|c|c|}
\hline \multirow[t]{3}{*}{ Localities } & \multirow[t]{3}{*}{ Species } & \multirow{3}{*}{$\begin{array}{l}\text { Number } \\
\text { Tested }\end{array}$} & \multicolumn{3}{|c|}{ Genotypes } & \multirow[t]{3}{*}{$f(1014 F)$} & \multirow[t]{3}{*}{$\mathrm{x}^{2}$-value } & \multirow[t]{3}{*}{ df } & \multirow[t]{3}{*}{$p$-value } \\
\hline & & & $1014 \mathrm{~F}$ & $1014 \mathrm{~L}$ & $1014 \mathrm{~L}$ & & & & \\
\hline & & & $1014 \mathrm{~F}$ & $1014 \mathrm{~F}$ & $1014 \mathrm{~L}$ & & & & \\
\hline \multirow[t]{2}{*}{ Kandi } & An. gambiae s.s & 90 & 58 & 25 & 7 & 0.78 & 0.0032 & 1 & 0.954 \\
\hline & An. arabiensis & 10 & 6 & 3 & 1 & 0.75 & & & \\
\hline \multirow[t]{3}{*}{ Parakou } & An. gambiae s.s & 94 & 64 & 23 & 7 & 0.80 & 0.720 & 2 & 0.697 \\
\hline & An. coluzzii & 3 & 2 & 0 & 1 & 0.67 & & & \\
\hline & An. arabiensis & 3 & 2 & 1 & 0 & 0.83 & & & \\
\hline Malanville & An. coluzzii & 100 & 37 & 44 & 19 & 0.59 & - & - & - \\
\hline
\end{tabular}

" $\mathrm{p}$-value: based on $\mathrm{x}^{2}$-square test comparing frequencies between the two species by locality; $\mathrm{f}=$ frequency

Table 5 The frequency of the ace-1 resistant allele (G119S) observed in different Anopheles gambiae complex species

\begin{tabular}{|c|c|c|c|c|c|c|c|c|c|}
\hline \multirow[t]{3}{*}{ Localities } & \multirow[t]{3}{*}{ Species } & \multirow{3}{*}{$\begin{array}{l}\text { Number } \\
\text { Tested }\end{array}$} & \multicolumn{3}{|c|}{ Genotypes } & \multirow[t]{3}{*}{$f(119 S)$} & \multirow[t]{3}{*}{$x^{2}$-value } & \multirow[t]{3}{*}{ df } & \multirow[t]{3}{*}{$p$-value } \\
\hline & & & $119 S$ & $119 G$ & $119 G$ & & & & \\
\hline & & & $119 S$ & $119 S$ & $119 G$ & & & & \\
\hline \multirow[t]{2}{*}{ Kandi } & An. gambiae s.s & 90 & 0 & 3 & 87 & 0.017 & 0.028 & 1 & 0.86 \\
\hline & An. arabiensis & 10 & 0 & 1 & 9 & 0.050 & & & \\
\hline \multirow[t]{3}{*}{ Parakou } & An. gambiae s.s & 94 & 0 & 5 & 89 & 0.027 & 0.327 & 2 & 0.84 \\
\hline & An. coluzzii & 3 & 0 & 0 & 3 & 0.000 & & & \\
\hline & An. arabiensis & 3 & 0 & 0 & 3 & 0.000 & & & \\
\hline Malanville & An. coluzzii & 100 & 0 & 6 & 94 & 0.030 & - & - & - \\
\hline
\end{tabular}

* $p$-value: based on the $x$ 2-square test comparing frequencies between the two species by locality; $f=$ frequency

Table 6). In Malanville and Kandi, significantly higher MFO levels were recorded in An. gambiae compared to the Kisumu strain $(\mathrm{p}<0.05)$ (Fig. 4). In contrast to Kandi, no significant activity of MFO was recorded in Parakou. The activity of glutathione-S-transferases (GST) is very close to those of Kisumu in the three communes.

\section{Discussion}

This study provides information about the intensity of insecticide resistance to deltamethrin, permethrin and bendiocarb in three communes of Benin. This study contributes to the knowledge base of insecticide resistance in Benin.

All three populations of An. gambiae showed high levels of resistance to the diagnostic dose of permethrin and deltamethrin, while suspected resistance was observed with bendiocarb in two study sites out of three. The pyrethroid resistance observed in the three communes confirms previous studies in Benin [3, 7, 20-22].

The lowest level of mortality to the diagnostic dose of permethrin was noted in Malanville (16\%). Increasing the permethrin dose $(5 \times$ and $10 \times)$ increased the mortality rate, but not all mosquitoes exposed to permethrinimpregnated papers died within $24 \mathrm{~h}$. The same was observed in Kandi and Parakou when An. gambiae populations were exposed to higher concentrations of permethrin $(5 \times$ and $10 \times$ diagnostic dose). For deltamethrin, there were very low mortality rates in Kandi $(16 \%)$ and Malanville (14\%) compared to Parakou (40\%). The use of $5 \times$ and $10 \times$ the diagnostic dose of deltamethrin showed strong resistance in Parakou with $49 \%$ mortality for the $5 \times$ dose and $73 \%$ for the $10 \times$ dose. Based on WHO guidelines [10], these results suggest that resistance levels in the three sites in northern Benin ranged from moderate to high for both deltamethrin and permethrin.

The $k d r 1014 \mathrm{~F}$ allele was found at very high frequencies in all tested An. gambiae populations, suggesting near fixation in the mosquito population. This spread of the $k d r$ 1014F gene in malaria vector populations in Benin could compromise the effectiveness of the vector control tools that are currently in use [23, 24].

Biochemical data revealed over-production of MFOs in An. gambiae populations in Kandi and Malanville localities, which was similar to previous studies conducted in these areas $[4,5]$. This finding is significant since oxidases 

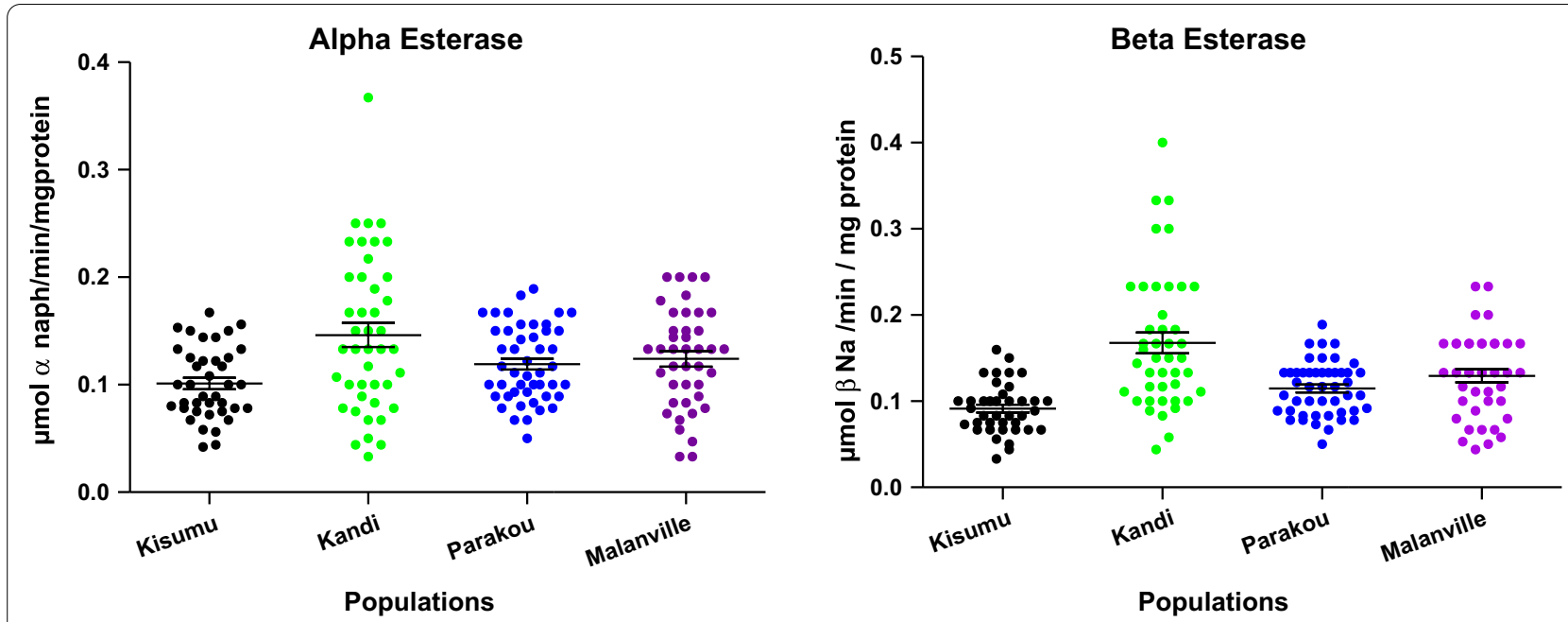

Populations
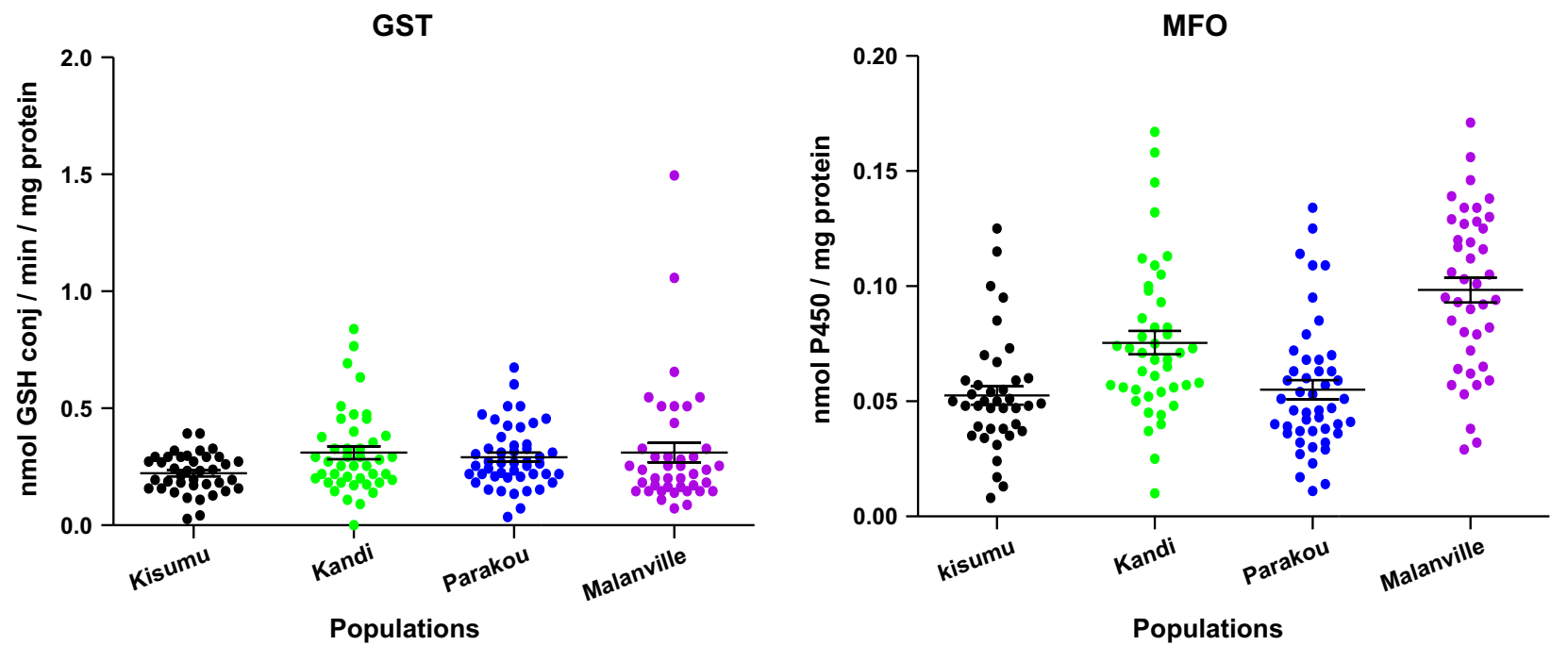

Fig. 4 Mean and standard error of enzyme overexpression [a- and $\beta$ - esterases, mixed-function oxidases (MFO) and glutathione-S-transferase (GST)] in Anopheles gambiae s.l. in Kandi, Parakou and Malanville compared with Anopheles gambiae s.s Kisumu (laboratory reference strain) characterized by spectrophotometry

Table 6 Comparison and statistical analysis of the mean and standard error of the enzymatic activity of the mixed-function oxidases, glutathione-S-transferases, and esterases in Anopheles gambiae populations

\begin{tabular}{lllll}
\hline $\begin{array}{l}\text { Mosquito } \\
\text { Population }\end{array}$ & $\begin{array}{l}\text { MFO (Absorbance } \\
\mathbf{6 3 0} \mathbf{n m})\end{array}$ & $\begin{array}{l}\text { GST (CDNA-n,mol/min/mg } \\
\text { protein) }\end{array}$ & $\begin{array}{l}\text { a-Esterase (a-nmol/min/mg } \\
\text { protein) }\end{array}$ & $\begin{array}{l}\boldsymbol{\beta} \text {-Esterase } \\
(\boldsymbol{\beta} \text {-nmol/min/mg } \\
\text { protein) }\end{array}$ \\
\hline Reference (Kisumu) & $0.052 \pm 0.004$ & $0.222 \pm 0.013$ & $0.101 \pm 0.005$ & $0.091 \pm 0.004$ \\
Kandi & $0.075 \pm 0.005^{\mathrm{a}, \mathrm{d}}$ & $0.310 \pm 0.027^{\mathrm{a}}$ & $0.146 \pm 0.011^{\mathrm{a}, \mathrm{d}}$ & $0.167 \pm 0.012^{\mathrm{a}}$ \\
Parakou & $0.055 \pm 0.004^{\mathrm{b}}$ & $0.291 \pm 0.019^{\mathrm{a}}$ & $0.119 \pm 0.005^{\mathrm{b}}$ & $0.114 \pm 0.004^{\mathrm{a}}$ \\
Malanville & $0.098 \pm 0.005^{\mathrm{c}, \mathrm{d}}$ & $0.310 \pm 0.041^{\mathrm{a}, \mathrm{d}}$ & $0.124 \pm 0.007^{\mathrm{b}}$ & $0.129 \pm 0.007^{\mathrm{a}}$ \\
One Way ANOVA & $\mathrm{F}=20.16 ;$ & $\mathrm{F}=2.18 ;$ & $\mathrm{F}=5.87 ;$ & $\mathrm{F}=16.52 ;$ \\
& $\mathrm{df}=4 ; 166 ;$ & $\mathrm{df}=4 ; 166 ;$ & $\mathrm{df}=4 ; 166 ;$ & $\mathrm{df}=4 ; 166 ;$ \\
& $\mathrm{p}<0.0001$ & $\mathrm{p}=0.009$ & $\mathrm{p}=0.0001$ & \\
\end{tabular}

MFO mixed function oxidases, GST glutathione-S-transferase;

Mean followed by a different letter were significantly different, $\mathrm{P}<0.05$, Tukey's test

${ }^{d}$ Significant increase in mean differences compared to the laboratory reference strain, $p<0.05$ using t-test 
are involved in the detoxification of pyrethroids in insects $[25,26]$.

Likely, the low mortality rates recorded with the diagnostic doses of pyrethroids in the three communes may be due to the very high insecticide selection pressure exerted on mosquitoes in these localities, characterized by massive cotton production and high use of chemicals to control pests. Additionally, ITNs and locally acquired mosquito avoidance pesticides (i.e., sprays and coils) may also contribute to the selection pressure. Resistance due to cotton cultivation in the north of the country has been reported by other authors [27, 28]. In Parakou, specifically, resistance could also be explained by the usage of insecticide products in market gardening. In addition to agricultural products, resistance may be further compounded by insecticidal pressures resulting from the massive use of LLINs $[29,30]$. High selection pressure from LLINs and pervasive use of insecticides in agriculture has been implicated in the high oxidase levels in An. gambiae s.s. populations [29, 31]. Thus, the simultaneous presence of the $k d r$ 1014F gene and elevated expression of oxidases may explain the high pyrethroid resistance intensities of malaria vectors observed in the two localities.

Given the status of pyrethroid resistance in these three areas, new generation LLINs treated with a pyrethroid and piperonyl butoxide (PBO) should be considered for distribution. Also, the use of nets impregnated with a pyrethroid combined with $\mathrm{PBO}$ may improve the effectiveness of LLINs in areas with high levels of MFOs [32, 33]. However, the potential limitation of this study was that synergistic bioassays with PBO were not conducted. It should be noted that the high GST activity found in wild populations of An. gambiae in Kandi may play a minor role in pyrethroid resistance due to detoxification of pyrethroid-induced lipid peroxidation products [34]. Suspected resistance to bendiocarb was also noted. This was previously observed in several localities in Benin [3, $7,15]$. However, the existence of mosquitoes surviving after exposure to doses five times higher than the diagnostic dose in Kandi may indicate that moderate resistance intensity to bendiocarb is developing in northern Benin. At the time of this study, bendiocarb was being considered for IRS in Benin. However, bendiocarb was not used for IRS in Benin in 2017, and the organophosphate pirimiphos-methyl was used instead.

Generally, ace-1R resistance alleles and esterases are associated with resistance to carbamates and organophosphates. In this study, ace-1R resistance allele frequencies in the three localities were 2.0 to $2.5 \%$ depending on the locality. Previous studies reported ace- $1 R$ resistance allele frequency of 0 to $1 \%[4,15,20$, 35 . These results could indicate that the frequency of the ace- $1 R$ mutation is on the rise in Benin. However, the small sample size and the different locations used in this study from previous reports prevent confirming this increase in ace-1R with certainty. Recent results obtained by Aikpon et al. in Atacora [3], Gnanguenon et al. in Kandi [15], and Salako et al. in Alibori and Donga [7] have also shown 1 to $6 \%$ in ace-1R allele frequencies in different areas of northern Benin. Moreover, the high activity of non-specific esterases noted in Kandi shows that bendiocarb resistance may not be linked to the presence of the ace-1R mutation only. Esterases can confer resistance to organophosphates and carbamates [34]. This overproduction of esterases is thought to be due to insecticidal pressure exerted on mosquito larvae in cotton crops to control the pests [22,27]. This evolution of bendiocarb resistance coupled with the spread of the ace1 mutation allele in these mosquito populations could have serious implications for future IRS success. The insecticide rotation conducted during IRS in 2017 could curb the selection pressure of carbamate and organophosphate resistance in these populations and improve the effectiveness of pyrimiphos-methyl IRS in the area. However, it would be necessary to monitor the susceptibility of Anopheles to pyrimiphos-methyl and to find alternative vector control methods to curb the spread of resistance genes. Rotation or combination of insecticides in IRS are strategies to be promoted for resistance management, which is becoming an issue of concern.

\section{Conclusion}

This study provides information on the intensity of resistance of malaria vectors to insecticides used in LLINs and IRS in Benin. These findings not only confirm the results of past studies of widespread loss of susceptibility to permethrin and deltamethrin but also show that the intensity of resistance is moderate to high in An. gambiae in different parts of Benin. This high intensity of resistance is a potential threat to vector control efficacy. The mechanisms of resistance may include the presence of the $k d r$ L1014F gene and the overproduction of oxidases for the pyrethroids and increased activity of esterases for resistance to bendiocarb. Intensity results with pyrethroids suggest that alternatives to standard LLINs should be considered for use in northern Benin. Resistance assays with the insecticides alpha-cypermethrin, chlorfenapyr, and the synergist $\mathrm{PBO}$ should be routinely conducted as the scale-up of the distribution of new-generation nets (i.e., PBO ITNs or G2 ITNs) increases across sub-Saharan Africa. The results from these assays would serve as a guide in the choice of control strategies implemented by national malaria control programmes. 


\section{Abbreviations}

IRS: Indoor residual spraying; PMI: US President's Malaria Initiative; USAID: US Agency for International Development; WHO: World Health Organization; LLIN: Long-lasting insecticidal nets; NMCP: National malaria control programme; EIR: Entomological inoculation rate; PCR: Polymerase chain reaction; CREC: Centre de Recherche Entomologique de Cotonou; RTI: Research triangle international; ITN: Insecticide-treated net; CDC: Centers for disease control and prevention; MFO: Mixed function oxidases; GST: Glutathione S-transferases; CDNB: 1-Chloro-2,4-dinitrobenzene; TMBZ: Tetramethyl benzidine; ANOVA: Analysis of variance; $\mathrm{PBO}$ : Piperonyl butoxide.

\section{Acknowledgements}

The findings and conclusions in this manuscript are those of the authors and do not necessarily represent the official views of the US Centers for Disease Control and Prevention (CDC), the US Agency for International Development (USAID), or the US President's Malaria Initiative (PMI). Use of trade names is for identification only and does not imply endorsement by the CDC, USAID, PMI or the US Department of Health and Human Services.

\section{Authors' contributions}

MCA, RO, and GGP conceived the study. MCA, HWS, WS, FD, RO, GGP, FD, ASS and GGP have participated in the design of the study. Entomologic data was collected by RO, ASS, HWS, AAS and GGP and laboratory analysis was carried out by AS, RO, PGG and ASS. CDK drafted the manuscript. Statistical data analysis by ASS. DI, PC, ASH, FD, HWS, RO, ASS, PGG and MCA critically revised the manuscript for intellectual content. All authors read and approved the final manuscript.

\section{Funding}

This study was supported by the US President's Malaria Initiative through the US Agency for International Development (USAID).

\section{Availability of data and materials}

The data used and/or analysed in this study are available from the corresponding author on reasonable request.

\section{Declarations}

\section{Ethics approval and consent to participate}

Not applicable.

\section{Consent for publication}

Available (cleared_01062021).

\section{Competing interests}

The authors declare that they have no competing interests.

\section{Author details}

${ }^{1}$ Centre de Recherche entomologique de Cotonou (CREC), Cotonou, Bénin.

${ }^{2}$ Faculté des Sciences et Techniques de I'Université d'Abomey-Calavi, Abomey-Calavi, Bénin. ${ }^{3}$ US President's Malaria Initiative, US Agency for International Development, Cotonou, Bénin. ${ }^{4}$ Université Nationale d'Agriculture de Porto-Novo, Porto-Novo, Bénin. ${ }^{5}$ US President's Malaria Initiative, Centers for Disease Control and Prevention for Disease Control (CDC), Georgia, USA. ${ }^{6}$ Present Address: Bill \& Melinda Gates Foundation, Lagos, Nigeria.

Received: 13 January 2021 Accepted: 16 July 2021

Published online: 27 July 2021

\section{References}

1. WHO: World malaria report 2017. Geneva, World Health Organization, 2017

2. Ministry of Health (Benin): Benin Health Statistical Yearbook 2016. Ministry of Health (Benin), Porto-Novo, Benin; 2017.

3. Aikpon R, Agossa F, Osse R, Oussou O, Aizoun N, Oke-Agbo F, et al. Bendiocarb resistance in Anopheles gambiae s.l. populations from Atacora department in Benin, West Africa: a threat for malaria vector control. Parasit Vectors. 2013.6:192
4. Aizoun N, Aikpon R, Gnanguenon V, Oussou O, Agossa F, Padonou G, et al. Status of organophosphate and carbamate resistance in Anopheles gambiae sensu lato from the south and north Benin. West Africa Parasit Vectors. 2013;6:274.

5. Djegbe I, Boussari O, Sidick A, Martin T, Ranson H, Chandre F, et al. Dynamics of insecticide resistance in malaria vectors in Benin: first evidence of the presence of L1014S kdr mutation in Anopheles gambiae from West Africa. Malar J. 2011;10:261.

6. Yadouleton AW, Padonou G, Asidi A, Moiroux N, Bio-Banganna S, Corbel $V$, et al. Insecticide resistance status in Anopheles gambiae in southern Benin. Malar J. 2010;9:83.

7. Salako AS, Ahogni I, Kpanou C, Sovi A, Azondekon R, Sominahouin AA, et al. Baseline entomologic data on malaria transmission in prelude to an indoor residual spraying intervention in the regions of Alibori and Donga, Northern Benin. West Africa Malar J. 2018;17:392.

8. Chukwuekezie O, Nwosu E, Nwangwu U, Dogunro F, Onwude C, Agashi $\mathrm{N}$, et al. Resistance status of Anopheles gambiae (s/) to four commonly used insecticides for malaria vector control in South-East Nigeria. Parasit Vectors. 2020. 13:152.

9. Grau-Bové X, Lucas E, Pipini D, Rippon E, van 't Hof AE, Constant E, et al. Resistance to pirimiphos-methyl in West African Anopheles is spreading via duplication and introgression of the ace1 locus. PLoS Genet. 2021;17:e1009253.

10. WHO. Test procedures for insecticide resistance monitoring in malaria vector mosquitoes - 2nd Edn. Geneva, World Health Organization, 2016.

11. Brogdon WG, Chan A. Guideline for evaluating insecticide resistance in vectors using the CDC bottle bioassay. Atlanta USA: U.S. Centers for Disease control and Prevention; 2010.

12. INSAE. Effectifs de la population des villages et quartiers de ville du Benin (RGPH-4, 2013). Porto-Novo, Benin: Institut National de la Statistique et de l'analyse Economique; 2016.

13. Yadouleton A, Martin T, Padonou G, Chandre F, Asidi A, Djogbenou L, et al. Cotton pest management practices and the selection of pyrethroid resistance in Anopheles gambiae population in northern Benin. Parasit Vectors. 2011;4:60

14. Ahoyo Adjovi N, Guidibi E.: Monographie de la Commune Kandi. pp. 1-40. Cotonou, Benin: Cabinet Afrique Conseil; 2006:1-40.

15. Gnanguenon V, Agossa FR, Badirou K, Govoetchan R, Anagonou R, OkeAgbo $F$, et al. Malaria vectors resistance to insecticides in Benin: current trends and mechanisms involved. Parasit Vectors. 2015;8:223.

16. Santolamazza F, Calzetta M, Etang J, Barrese E, Dia I, Caccone A, et al. Distribution of knock-down resistance mutations in Anopheles gambiae molecular forms in west and west-central Africa. Malar J. 2008;7:74.

17. MartinezTorres D, Chandre F, Williamson MS, Darriet F, Berge JB, Devonshire AL, et al. Molecular characterization of pyrethroid knockdown resistance $(k d r)$ in the major malaria vector Anopheles gambiaess. Insect Mol Biol. 1998.7:179-84.

18. Weill M, Malcolm C, Chandre F, Mogensen K, Berthomieu A, Marquine $M$, et al. The unique mutation in ace-1 giving high insecticide resistance is easily detectable in mosquito vectors. Insect Mol Biol. 2004;13:1-7.

19. MR4. Methods in Anopheles Research. Atlanta USA: Centers for Disease Control and Prevention; 2015.

20. Corbel V, N'Guessan R, Brengues C, Chandre F, Djogbenou L, Martin $T$, et al. Multiple insecticide resistance mechanisms in Anopheles gambiae and Culex quinquefasciatus from Benin. West Africa Acta Trop. 2007;101:207-16.

21. Djogbenou L, Pasteur N, Bio-Bangana S, Baldet T, Irish SR, Akogbeto M, et al. Malaria vectors in the Republic of Benin: distribution of species and molecular forms of the Anopheles gambiae complex. Acta Trop. 2010;114:116-22.

22. Yadouleton AW, Asidi A, Djouaka RF, Braima J, Agossou CD, Akogbeto MC. Development of vegetable farming: a cause of the emergence of insecticide resistance in populations of Anopheles gambiae in urban areas of Benin. Malar J. 2009;8:103.

23. Chouaibou M, Etang J, Brevault T, Nwane P, Hinzoumbe CK, Mimpfoundi $R$, et al. Dynamics of insecticide resistance in the malaria vector Anopheles gambiae s.l. from an area of extensive cotton cultivation in Northern Cameroon. Trop Med Int Health. 2008;13:476-86. 
24. N'Guessan R, Corbel V, Akogbéto M, Rowland M. Reduced efficacy of insecticide-treated nets and indoor residual spraying for malaria control in pyrethroid resistance area. Benin Emerg Infect Dis. 2007;13:199-206.

25. Ishaaya I. Insect detoxifying enzymes: their importance in pesticide synergism and resistance. Arch Insect Biochem Physiol. 1993;22:263-76.

26. Miller TA. Mechanisms of resistance to pyrethroid insecticides. Parasitol Today. 1988:4:S8-12.

27. Akogbeto MC, Djouaka RF, Kinde-Gazard DA. Screening of pesticide residues in soil and water samples from agricultural settings. Malar J. 2006;5:22.

28. Diabate A, Baldet T, Chandre F, Akogbeto M, Guiguemde TR, Darriet F, et al. The role of agricultural use of insecticides in resistance to pyrethroids in Anopheles gambiae s.l. in Burkina Faso. Am J Trop Med Hyg. 2002;67:617-22.

29. Omondi S, Mukabana WR, Ochomo E, Muchoki M, Kemei B, Mbogo C, et al. Quantifying the intensity of permethrin insecticide resistance in Anopheles mosquitoes in western Kenya. Parasit Vectors. 2017;10:548.

30. Protopopoff N, Verhaeghen K, Van Bortel W, Roelants P, Marcotty T, Baza D, et al. A significant increase in $k d r$ in Anopheles gambiae is associated with an intensive vector control intervention in Burundi highlands. Trop Med Int Health. 2008;13:1479-87.

31. Ochomo E, Bayoh MN, Brogdon WG, Gimnig JE, Ouma C, Vulule JM, et al. Pyrethroid resistance in Anopheles gambiae and Anopheles arabiensis in western Kenya: phenotypic, metabolic and target site characterizations of three populations. Med Vet Entomol. 2013. 27:156-64.

32. Oumbouke WA, Rowland M, Koffi AA, Aliou PA, Camara S N'Guessan R. Evaluation of an alpha-cypermethrin + PBO mixture long-lasting insecticidal net VEERALIN ${ }^{\circledR}$ LN against pyrethroid resistant Anopheles gambiae s.s.: an experimental hut trial in M'bé, central Côte d'Ivoire. Parasit Vectors. 2019. 12:544.

33. Gleave K, Lissenden N, Richardson M, Choi L, Ranson H. Piperonyl butoxide (PBO) combined with pyrethroids in insecticide-treated nets to prevent malaria in Africa. Cochrane Database Syst Rev. 2018. 11:CD012776.

34. Hemingway J, Hawkes NJ, McCarroll L, Ranson H. The molecular basis of insecticide resistance in mosquitoes. Insect Biochem Mol Biol. 2004;34:653-65.

35. Djenontin A, Chandre F, Dabire KR, Chabi J, N'Guessan R, Baldet T, et al. Indoor use of plastic sheeting impregnated with carbamate combined with long-lasting insecticidal mosquito nets for the control of pyrethroidresistant malaria vectors. Am J Trop Med Hyg. 2010;83:266-70.

\section{Publisher's Note}

Springer Nature remains neutral with regard to jurisdictional claims in published maps and institutional affiliations.
Ready to submit your research? Choose BMC and benefit from:

- fast, convenient online submission

- thorough peer review by experienced researchers in your field

- rapid publication on acceptance

- support for research data, including large and complex data types

- gold Open Access which fosters wider collaboration and increased citations

- maximum visibility for your research: over 100M website views per year

At BMC, research is always in progress.

Learn more biomedcentral.com/submissions 